\title{
PERSONALITY SUBTYPES IN FEMALE PRE-BARIATRIC OBESE PATIENTS: DO THEY DIFFER IN EATING DISORDER SYMPTOMS, PSYCHOLOGICAL COMPLAINTS AND COPING BEHAVIOR?
}

Laurence Claes $^{1}$, Walter Vandereycken ${ }^{1,2}$, An Vandeputte ${ }^{2}, \&$ Caroline Braet $^{2,3}$

${ }^{1}$ Department of Psychology, Catholic University of Leuven, Leuven, Belgium

${ }^{2}$ Eetexpert.be, Bergestraat 60, 3220 Holsbeek, Belgium

${ }^{3}$ Department of Psychology, University of Ghent, Ghent, Belgium

\section{Corresponding author:}

Laurence Claes, KUL Department of Psychology, Tiensestraat 102, B-3000 Leuven, Belgium.

E-mail: Laurence.claes@ppw.kuleuven.be; phone: +32-16-326133; fax: +32-16-325916

\section{Acknowledgment}

The authors like to thank the following members of the Obesity Task Force of Eetexpert.be for their help with data-collection: Bex Annelies, Boekaerts Els, Brants Lies, Brunelli Barbara, Dhaene Sophie, D'Haese Katrien, Gijbels Sylvia and Strauven An. 


\begin{abstract}
In the pre-bariatric psychological assessment of 102 morbidly obese females, two personality subtypes emerged: a Resilient/High Functioning (RHF) subtype with a 'normal' personality profile, and an Emotional Dysregulated/Undercontrolled (EDU) subtype, characterized by high neuroticism and low extraversion/conscientiousness. EDU patients showed more concerns about eating/weight/shape, more binge-eating driven by emotions and external triggers, more psychological complaints (such as depression and anxiety) and more avoidance and depressive coping reactions than RHF patients. Further research should clarify whether these clearly different psychological profiles are related to different outcomes (weight loss, well-being) of bariatric surgery.
\end{abstract}

Key words: obesity, psychological assessment, personality types, eating disorders, bariatric surgery, 


\section{Introduction}

In most western industrialized countries, obesity has become a major health problem. In $2008,13 \%$ of the male and $14 \%$ of the female adult population in Belgium showed a body mass index $\left[\mathrm{BMI}=\right.$ weight in $\left.\mathrm{kg} /(\text { length in meters })^{2}\right] \geq 30$, with the highest prevalence of obesity in the age range 55-64 (Drieskens, 2008). Bariatric surgery as treatment for severe (BMI 35-49) and morbid (BMI $\geq 40$ ) obesity can offer a satisfying solution for the patient confronted with the physical and psychological risks and consequences (van den Oever \& Volckaert, 2006). Many studies (for overview, see Müller et al., 2012) have made a differentiation between obese patients with and without binge eating disorder (BED): differences were found in terms of eating attitudes and behavior (Hsu et al., 2002; Wilfley, Schwartz, Spurrell, \& Fairburn, 2000), comorbid psychopathology (Jones-Corneille et al., 2012; Mühlans et al., 2009; Rosenberger, Henderson, \& Grilo, 2006) and personality disorders/traits (e.g., Auchenbach-Barber, 1998; Bulik et al., 2002; Fassiono et al., 2002; Specker et al., 1994; Van Hanswijck et al., 2003). So it seems that there exist different subgroups in obese patients, with different needs among these patients. By assessingthe pretreatment characteristics of patients we may be able to tailor treatments to the individual patients’ needs (Braet \& Beyers, 2009).

Eating pathology markers - eating disorder symptoms in general and dietary restraint in particular - may indicate a poor prognosis in obese patients with binge eating problems and have been associated with excessive weight gain. Therefore, Grilo, Masheb, and Wilson (2001) tried to identify subtypes based on the presence or absence of particular eating disorder symptoms and psychopathology. Cluster analysis revealed a dietary-negative affect subtype and a pure dietary subtype. Remarkable, the subtype characterized with high scores on negative affect appears to be related to poorer treatment response. Hence, assessing a broader range of pre-treatment characteristics besides eating disorder symptoms can be useful 
in developing an optimal treatment plan matched to the patients' strengths and weaknesses. Therefore, the the present study is aimed at differentiating subtypes in morbidly obese prebariatric patients in correlation with eating disorder pathology, psychological symptoms and coping styles.

Up till now, there exist surprisingly few studies that focus on subgroups in adult obese patients. Only Jansen, Havermans, Nederkoorn, and Roefs (2008) performed a cluster analysis in a community sample of overweight and obese people, and found a cluster high in negative affect and another one low in negative affect. There were no differences in BMI between both clusters, but patients in the high negative affect cluster showed more frequent binge eating and more body-related worrying. So it seems important to test also in obese pre-bariatric samples if there exists a subtype of patients characterized by emotional dysregulation which is assumed to induce emotional eating (Grilo et al., 2001) and binge eating, known as maladaptive coping strategies that complicate weight loss. Furthermore, if we find these subtypes in obese pre-bariatric samples, we can plead for more psychological support and fine-tuned interventions specifically in the emotionally dysregulated subgroup.

Previous research in eating disorder patients, based on the Neuroticism, Extraversion, Openness-Five Factor Inventory (NEO-FFI), showed three personality clusters: a dysregulated/undercontrolled cluster, characterized by elevated scores on Neuroticism and low scores on Conscientiousness and Agreeableness; a constricted/overcontrolled cluster, characterized by high scores on Neuroticism and Conscientiousness and low scores on Openness to Experience; and a high-functioning/resilient cluster without pronounced personality pathology (Claes et al., 2006; Thompson-Brenner \&Westen, 2005). Remarkably, differentiation on other dimensions like personality characteristics has not yet been explored in obese samples but certainly worthwhile to consider. Expanding the findings of Jansen et al. (2008) in a community sample, the first aim of the present study is to find out whether we can 
identify different personality subtypes in a sample of pre-bariatric obese patients, based on the Big Five personality dimensions. This approach is recognized as the most comprehensive way of characterizing people (Markon, Krueger, \& Watson, 2005). Moreover, based on the Big Five personality traits, it is also possible to identify highly resilient people (e.g., Claes et al., 2006). If subtyping is possible based on one test covering the most important personality characteristics, it is a cost-effective way of assessing pretreatment characteristics.

Interestingly, the personality profiles in eating disorders are characterized by differences on a broad range of patient characteristics (coping skills, depression, interpersonal functioning, impulsivity) on which treatment techniques can be focused (e.g., Claes et al., 2006; Thompson-Brenner \& Westen, 2005). However, litlle is known about the fact whether obese subtypes also differ on these patient characteristics. Therefore, as a second aim we want to study whether also in obese samples there exists a personality subtype showing more eating disorder-related symptoms (e.g., binge eating), more psychological symptoms (e.g., depression,) and more maladaptive coping behaviors (e.g., less active problem solving).

\section{Method}

\section{Participants}

The original sample consisted of 135 female obese patients who were psychologically screened as part of their pre-bariatric surgery assessment. We have excluded 10 patients who did not complete the assessment and 23 patients who already underwent a surgical intervention for their obesity (most often, gastric banding). The mean BMI of the remaining sample $(\mathrm{n}=102)$ was $40.7(S D=4.16$; range $31-52): 2.9 \%(\mathrm{n}=3)$ suffered from obesity grade 1 (BMI 30-34.9), 26.5\% $(\mathrm{n}=27)$ from obesity grade 2 (BMI 35-39.9) and 70.6\% $(\mathrm{n}=72)$ from obesity grade $3(\mathrm{BMI} \geq 40)$. The mean age of the sample was 36.4 year $(S D=10.86$; range 18 - 
64).With respect to medical co-morbidity (as noted in the patients' charts), $19.6 \%(\mathrm{n}=20)$ had high blood pressure, 22.5\% ( $\mathrm{n}=23)$ rheumatoid arthritis, $16.7 \%(\mathrm{n}=17)$ high levels of cholesterol, 13.7\% $(\mathrm{n}=14)$ diabetes type 2, 6.9\% $(\mathrm{n}=7)$ pulmonary disease, $1 \%(\mathrm{n}=1)$ a cerebrovascular accident, and 5.9\% $(\mathrm{n}=6)$ sleep apnea.

\section{Instruments}

To determine the personality prototypes, we made use of the Neuroticism, Extraversion, Openness to New Experience-Five Factor Inventory (NEO-FFI; Costa \& McCrae, 1992; Dutch version: Hoekstra, Ormel, \& de Fruyt, 1996). The NEO-FFI is a wellknown instrument to assess both normal and abnormal variants of personality functioning. Furthermore, previous research on personality subtypes in eating disorderpatients also used the NEO-FFF (e.g., Claes et al., 2006) which makes it possible to compare these findings with those in obese patients. The NEO-FFI is a 60 -item self-report measure of five major personality traits: Neuroticism, Extraversion, Openness to Experience, Agreeableness, and Conscientiousness. Items are answered on a five-point scale ranging from "strongly agree" to "strongly disagree". There is considerable evidence for the reliability and construct validity of the Dutch NEO-FFI (Hoekstra, Ormel, \& de Fruyt, 1996).

To assess the eating disorder-related problems in our present sample, we used the Eating Disorder Examination - Self-Report Questionnaire Version (EDE-Q; Fairburn \& Beglin, 1994). The EDE-Q is a 41-item measure adapted from the Eating Disorder Examination (EDE; Cooper \& Fairburn, 1987), a structured clinical interview assessing the key behavioral features and associated psychopathology of eating disorders. The EDE-Q consists of four subscales: Restraint, Weight Concern, Shape Concern, and Eating Concern. Luce and Crowther (1999) reported excellent internal consistency and test-retest reliability for the four subscales.

Opmerking [C1]: Met je de alpha (interne consistentie) niet vermelden van je instrumenten in deze studie? 
To get a better idea of the factors which trigger binge-eating episodes, we also appplied the Dutch Eating Behavior Questionnaire (DEBQ, Van Strien, Frijters, Bergers, \& Defares, 1986). This 33-item self-report questionnaire, to be rated on a 5-point scale, assesses three separate factors of eating behavior: restrained eating (items related to weight control), emotional eating (eating related to emotional states), and external eating (eating related to external cues). Several studies have confirmed the convergent, discriminative, and concurrent validity of the DEBQ (Van Strien et al., 1986).

To assess affective and interpersonal psychopathology, we made use of the Symptom Checklist (SCL-90; Dutch version: Arrindell \& Ettema, 1986). The SCL-90 is a well-known measure for the assessment of a wide range of psychiatric symptoms. It exists of 90 items (symptoms) to be rated on a 5-point scale ranging from "not at all applicable" to "strongly applicable". Along with a global measure for psychoneuroticism, it measures symptoms of general anxiety, phobic anxiety, depression, somatization, obsessions/compulsions, paranoid ideation and interpersonal sensitivity, hostility, and sleeplessness. The validity studies of the SCL-90 demonstrate "good" to "very good" levels of concurrent, convergent, discriminant and construct validity (Arrindell \& Ettema, 1986).

Finally, to assess the adaptive and maladaptive coping strategies of our patients we used the Utrecht Coping List (UCL; Schreurs, van de Willige, Brosschot, Tellegen, \& Graus, 1993). The UCL consists of 47 items rated on a 4-point scale and divided across seven scales that measure a variety of different coping strategies and techniques: Active Problem Solving, Palliative Reactions, Passive/Depressive Reactions, Avoidance, Social Support Seeking, Expression of Emotions, and Self-Soothing Thoughts. There is considerable evidence for the reliability and construct validity of the UCL (Schreurs et al., 1993). 
To determine the personality subtypes in our sample, cluster analysis was performed on the five NEO-FFI personality scales by means of the K-means cluster analysis procedure provided by SPSS19. To cross-validate the obtained cluster solution, we also performed a model-based cluster analysis using the S-PLUS 8 software program and the MCLUST library (Fraley \& Raftery, 2003). To externally validate the clusters, we performed MANOVAs with the personality clusters as independent variable and the demographic variables, eatingdisorder symptoms, psychological symptoms and coping strategies as dependent variables.

\section{Results}

\section{Personality Subtypes}

\section{Insert Figure 1 about here}

The cluster analyses revealed that a two cluster solution fitted the data best. In Figure, 1, mean z-standardized NEO-FFI scale scores for the two subtypes in the total sample are presented. The first subtype (on the left) is characterized by a negative score on Neuroticism and positive scores on Extraversion, Openness, Agreeableness, and Conscientiousness; whereas the second subtype (on the right) is characterized by the opposite pattern. Based on the literature (e.g., Asendorph et al., 2001), patients of subtype $1(\mathrm{n}=44,43.1 \%)$ are therefore called Resilient/High Functioning (RHF); whereas patients of subtype $2(\mathrm{n}=58 ; 56.9 \%)$ are called Emotionally Dysregulated/Undercontrolled (EDU). The results of the MANOVA with 
the personality clusters as independent variable and the NEO-FFI scales as dependent variables (Table 1), showed significant differences between the two clusters on all NEO-FFI scales [Wilks'Lambda $=0.36, \mathrm{~F}(5,96)=33.16, \mathrm{p}<0.001$ ]. Compared to data of normal controls the RHF group scored above the mean on Extraversion, Agreeableness and Conscientiousness, and below the mean on Neuroticism; whereas the opposite pattern held for the EDU group.

Insert Table 1 about here

Personality Subtypes and Demographic Characteristics

With respect to age, we did not find significant differences between RHF patients $\left[\mathrm{M}_{\mathrm{age}}=38.61, \mathrm{SD}=9.93\right]$ and $\mathrm{EDU}$ patients $\left[\mathrm{M}_{\mathrm{age}}=34.73, \mathrm{SD}=11.34\right] \quad[F(1,97)=3.19, n s]$. Similarly, RHF patients did not significantly differ from EDU patients with respect to the level of education $\left[\chi_{(3)}=3.33, n s\right]$. The distribution of education for the RHF/EDU patients was as follows: elementary school (4.7\% vs. $11.1 \%)$; secondary school $(60.5 \%$ vs. $66.7 \%)$, higher education outside university (30.2\% vs. $16.7 \%)$ and university (4.7\% vs. $5.6 \%)$. The current BMI of the RHF patients was similar to the BMI of the EDU patients, and the same results were found for weight fluctuations (Table 2).

\section{Personality Subtypes and Eating Disorder-Related Symptoms}

We found significant differences between EDU and RHF patients with respect to the EDE-Q scales [Wilks'Lambda $=0.75, F(4,82)=6.71, p<0.001]$. The EDU patients scored
Opmerking [C2]: Moet je niet vooraf in een analyse paragraaf zeggen dat je dat altijd gaat vergelijken met een one-way $\mathrm{t}$ test met de data in handleidingen over de normale controles?? Als het hier in de resultsectie staat lijkt het me wel logisch dat je dan de t-waarde ook vermeldt Ofwel gewoon in de discussie vermelden??

Opmerking [C3]: Mij lijkt het beter dat je dan de vgl met de EDU groep beschrijft nu trek je de aandacht voor de RHF

Opmerking [C4]: Lijkt mij beter onder de demografische factoren 
significantly higher on the EDE-Q Eating, Weight and Shape Concern scales than RHF patients; whereas no significant differences emerged with respect to the EDE-Q scale Restraint. With respect to eating-disorder related behaviors, EDU patients reported significantly more EDE-Q objective binge-eating episodes $\left[X^{2}{ }_{(1)}=4.21, p<0.05\right]$ than RHF patients. Finally, we found significant differences between EDU and RHF patients with respect to the DEBQ-scales [Wilks'Lambda $=0.86, F(3,92)=4.63, p<0.01]$. The EDU patients scored significantly higher on the DEBQ Emotional Eating and External Eating scales than RHF patients; whereas the RHF patients scored significantly higher than EDU patients on the DEBQ-scale Restraint Eating. When comparing the scores on emotional and external eating with data of normal controls, the EDU morbidly obese patients scored high on both scales; whereas the RHF group scored on the mean to above mean level.

Insert Table 2 about here

Personality Subtypes and Psychological Symptoms

Overall, EDU patients showed significantly more psychological symptoms than RHF patients [Wilks'Lambda $=0.65, F(9,85)=4.95, p<0.001]$ on the SCL-90: agoraphobia, anxiety, depression, somatisation, insufficiency of thinking, interpersonal sensitivity, hostility, psychoticism, and psychoneuroticism (total score) except for sleeping problems. Compared to data of normal controls, the EDU patients scored high to very high on all the SCL-90 scales, whereas the RHF group scored in the medium to above medium level. 


\section{Personality Subtypes and Coping Behavior}

Finally, we found significant differences between EDU and RHF patients with respect to coping behavior [Wilks'Lambda $=0.67, F(7,92)=6.39, p<0.001$ ]. RHF patients scored significantly higher on UCL-scale Active Problem Solving; whereas EDU patients scored significantly higher on the UCL-scales Palliative Reactions, Avoidant Coping, and Depressive Coping. Compared to data of normal controls, the EDU group scored high on palliative reactions, avoidant coping and depressive coping; whereas RHF scored high on active problem solving.

Insert Table 4 about here

\section{Discussion}

Our major aim was to to identify personality subtypes of morbidly obese female patients who applied for bariatric surgery and to investigate whether these subtypes showed differences in weight and eating behaviors, psychological complaints and coping strategies.

Based on the big 5 personality traits, we were able to identify two personality subtypes: a RHF subtype (43.1\%), with a 'normal' personality profile, and an EDU subtype (56.9\%), characterized by high Neuroticism, low Extraverion/Agreeableness and lower Conscientiousness. Obese people belonging to the latter subtype can be described as high on 
negative affect, with poor social contacts and less cognitive control. This replicates the findings of Jansen et al (2008) who was the first do identify in obese people two subtypes with one scoring high on negative affect. Personality subtypes were already identified in a group of female eating disorderpatients, in which on the basis of 4 of the 5 NEO-subscales also an EDU subtype was found, besides a RHF subtype and an overcontrolled (OC) subtype (Claes et al., 2006).An OC was not prevalent in our morbidly obese sample, but this is not surprising given that the Overcontrolled subtype was found primarily among restrictive anorexia nervosa patients, characterized by emotional instability but also rigidity/obsessiveness (Claes et al., 2006), a feature that is usually absent in morbidly obese patients.

With respect to eating-disorder related behaviors, EDU patients engaged significantly more in binge-eating compared to RHF patients, and their binge-episodes seemed primarily triggered by emotions Given their personality subtype characterized by high negative affect and more impulsive/less controlled nature of the EDU patients, it is not surprising that they easier give in into 'attractive' food cues compared to RHF patients. The correlations between Emotional Eating and Neuroticism $(r=.40)$, Extraversion $(r=-.26)$ and Conscientiousness $(r=-$ .32) confirm this hypothesis. The higher score on emotional eating in the EDU patients is in line with Elfhag and Morey (2008), who also found significant associations between emotional eating and high neuroticism, low extraversion and low conscientiousness

Compared to RHF patients, EDU patients also reported more concerns about their eating, weight and body shape although their actual BMI was similar (see also Jansen et al., 2008). Further, they have higher scores on anxiety- and depression-related symptoms, and higher scores on avoidance and depressive coping styles. This seems to indicate that the eating behavior of the EDU patients could have an emotion regulating function (avoiding or escaping from negative affect). The correlations between the scores of the EDEQ-subscales
Opmerking [C6]: Hier meot ergens de impulsive nature uitblijken en ook de undercontrol.. heb je nog wat adjectieven

uit de NEO om het type te beschrijven?
Opmerking [C7]: $\mathrm{Er}$ is geen correlatietabel waarbij je de AV zelf met elkaar correleert dus kan je daar geen uitspraken over doen. 
and the subscales of the SCL-90 and the UCL confirm this hypothesis. Similar findings were reported by Grilo et al. (2001) who showed that the negative affect subtype was characterized by more binge eating and less adequate emotion regulation strategies, which increases the probability of a poor outcome, given that eating behaviors were used as a coping strategy with the increase of weight as a negative consequence. In contrast, obese patients of the RHF subtype were characterized by lower degrees of weight concerns and psychological symptoms probably thanks to their more active coping styles (to deal with their problems).

Given that we were able to distinguish personality subtypes with different psychological profiles in our group of morbidly obese patients, further research is necessary to investigate whether these profiles also have predictive power with respect to the outcome of treatment in general, and bariatric surgery in particular, in terms of weight loss and general well-being. Such research is needed to guide the treatment of choice for patients with more at risk personality features and related psychopathology.

However, the results of this study are not without limitations. First of all, the sample consists of morbidly obese female patients who were all applying for bariatric surgery. The results of the study can therefore not be generalized to male patients and morbidly obese patients who are not seeking bariatric surgery. Furthermore, since patients came from different centers each using their own procedure of physical assessment, information on somatic comorbidity needs to be interpreted with caution. Finally, a more systematic psychiatric assessment, including Axis I and Axis II diagnoses, would be advisable but was not available in our study. 


\section{References}

Arrindell, W.A., \& Ettema, J.H.M (1986). SCL-90: Handleiding bij een multidimensionele psychopathologie-indicator [SCL-90 manual]. Lisse (Netherlands): Swets \& Zeitlinger.

Asendorpf, J.B., Borkenau, P., Ostendorf, F., \& van Aken, M.A.G. (2001). Carving personality description at its joints: Confirmation of three replicable personality prototypes for both children and adults. European Journal of Personality, 15, 169-198.

Auerbach-Barber, S. (1998). Interpersonal and personality correlates of obese binge eaters and non-binge eaters. Dissertation Abstracts International: Section B: The Sciences and Engineering, 59(3-B), 1357.

Braet, C. \& Beyers, W. (2009). Defining subtypes in children and adolescents who are overweight: Differences in symptomatology and treatment outcomes. Journal of Consulting and Clinical Psychology, 77, 814-824

Bulik, C.M., Sullivan, P.F., \& Kendler, K.S. (2002). Medical and psychiatric morbidity in obese women with and without binge eating. International Journal of Eating Disorders, 32, 72-78.

Claes, L., Vandereycken, W., Luyten, P., Soenens, B., Pieters, G., \& Vertommen, H. (2006). Personality prototypes in eating disorders based on the Big Five Model. Journal of Personality Disorders, 4, 401-416.

Costa, P.T., Jr., McCrae, R.R. (1992). Revised NEO Personality Inventory (NEO-PI-R) and the Five Factor Inventory (NEO-FFI): Professional manual. Odessa (FL): Psychological Assessment Resources. 
Cooper, Z., \& Fairburn, C.G. (1987). The Eating Disorder Examination: A semi-structured interview for the assessment of the specific psychopathology of eating disorders. International Journal of Eating Disorders, 6, 1-8.

Drieskens, S. (2008). Gezondheidsenquête: Voedingsstatus [Health survey: nutritional status]. Brussels: Wetenschappelijk Instituut Volksgezondheid.

Elfhag, K. \& Morey, L.C. (2008). Personality traits and eating behavior in the obese: Poor self-control in emotional and external eating but personality assets in restrained eating. Eating Behaviors, 9, 285-293.

Fairburn, C.G., \& Beglin, S.J. (1994). Assessment of eating disorders: Interview or self-report questionnaire. International Journal of Eating Disorders, 16, 363-370.

Fassino, S., Leombruni, P., Piero, A., Abbate Daga, G., Amianto, F., Rovera, G., \& Giacomo Rovera, G. (2002). Temperament and character in obese women with and without binge eating disorder. Comprehensive Psychiatry, 43, 431-437.

Fraley, C., \& Raftery, .E. (2003). Enhanced Model-Based Clustering, Density Estimation, and Discriminant Analysis Software: MCLUST. Journal of Classification, 20, 263-186.

Grilo, C. M., Masheb, R. M., \& Wilson, G. T. (2001). Subtyping binge eating disorder. Journal of Consulting and Clinical Psychology, 69, 1066-1072.

Hoekstra, H.A., Ormel, J., \& de Fruyt, F. (1996). NEO-PI-R en NEO-FFI Big Five persoonlijkheidsvragenlijsten. Handleiding [NEO-PI-R and NEO-FFI Big Five personality questionnaires. Manual]. Amsterdam: Swets \& Zeitlinger. 
Hsu, L.K., Mulliken, B., McDonagh, B., Krupa Das, S., Rand, W., Fairburn, C.G., et al. (2002). Binge eating disorder in extreme obesity. International Journal of Obesity, 26, 1398-1403.

Jansen, A., Havermans, R., Nederkoorn, C., \& Roefs, A. (2008). Jolly fat or sad fat? Subtyping non-eating disordered overweight and obesity along an affect dimension. Appetite, 51, 635-640.

Jones-Corneille, L.R., Wadden, T.A., Sarwer, D.B., Faulconbridge, L.F., Fabricatore, A.N., Stack, R.M., et al. (2012). Axis I psychopathology in bariatric surgery candidates with and without binge eating disorder: Results of structured clinical interviews. Obesity Surgery, 22, 389-397. .

Luce, K.H., \& Crowther, J.H. (1999). The reliability of the Eating Disorder Examination-SelfReport Questionnaire Version (EDE-Q). International Journal of Eating Disorders, $25,349-351$.

Markon, K.E., Krueger, R., \& Watson, D. (2005). Delineating the Structure of Normal and Abnormal Personality: An Integrative Hierarchical Approach. Journal of Personality and Social Psychology, 88, 139-157.

Müller, A., Claes, L., Mitchell, J.E., Fischer, J., Horbach, T., \& de Zwaan, M. (2012). Binge eating and temperament in morbidly obese prebariatric surgery patients. European Eating Disorders Review, 20, e91-95.

Mühlhans, B., Horbach, T., \& de Zwaan, M. (2009). Psychiatric disorders in bariatric surgery candidates: A review of the literature and results of a German prebariatric surgery sample. General Hospital Psychiatry, 31, 414-421. 
Rosenberger, P.H., Henderson, K.E., \& Grilo, C.M. (2006). Psychiatric disorder comorbidity and association with eating disorders in bariatric surgery patients: A cross-sectional study using structured interview-based diagnosis. Journal of Clinical Psychiatry, 67, $1080-1085$.

Sansone, R., Wiederman, M., \& Monteith, D. (2001). Obesity, borderline personality symptomatology, and body image among women in a psychiatric outpatient setting. International Journal of Eating Disorders, 29, 76-79.

Schreurs, P.J.G., van de Willige, G., Brosschot, J.F., Tellegen, B., \& Graus, G.M.H. (1993). De Utrechtse Coping Lijst: UCL [The Utrecht Coping List: UCL]. Lisse (Netherlands): Swets \& Zeitlinger.

Specker, S., de Zwaan, M., Raymond, N., \& Mitchell, J. (1994). Psychopathology in subgroups of obese women with and without binge eating disorder. Comprehensive Psychiatry, 35, 185-190.

Thompson-Brenner, H., \& Westen, D. (2005). Personality subtypes in eating disorders: Validation of a classification in a naturalistic sample. British Journal of Psychiatry, 186, 516-524.

Van den Oever, R., \& Volckaert, C. (2006). Bariatric surgery trends in Belgium: The health insurer's view. Acta Chirurgica Belgica, 106, 641-646.

van Hanswijck de Jonge, P., van Furth, E.F, Lacey, H., \& Waller, G. (2003). The prevalence of DSM-IV personality pathology among individuals with bulimia nervosa, binge eating disorder and obesity. Psychological Medicine, 33, 1311-1317. 
Van Strien, T., Frijters, J.E.R., Bergers, G.P.A., \& Defares, P.B. (1986). The Dutch Eating Behavior Questionnaire for assessment of restrained, emotional and external eating behavior. International Journal of Eating Disorders, 5, 295-315.

Wilfley, D.E., Schwartz, M., Spurrell, E., \& Fairburn, C. (2000). Using the eating disorder examination to identify the specify psychopathology of binge eating disorder. International Journal of Eating Disorders, 27, 259-269. 


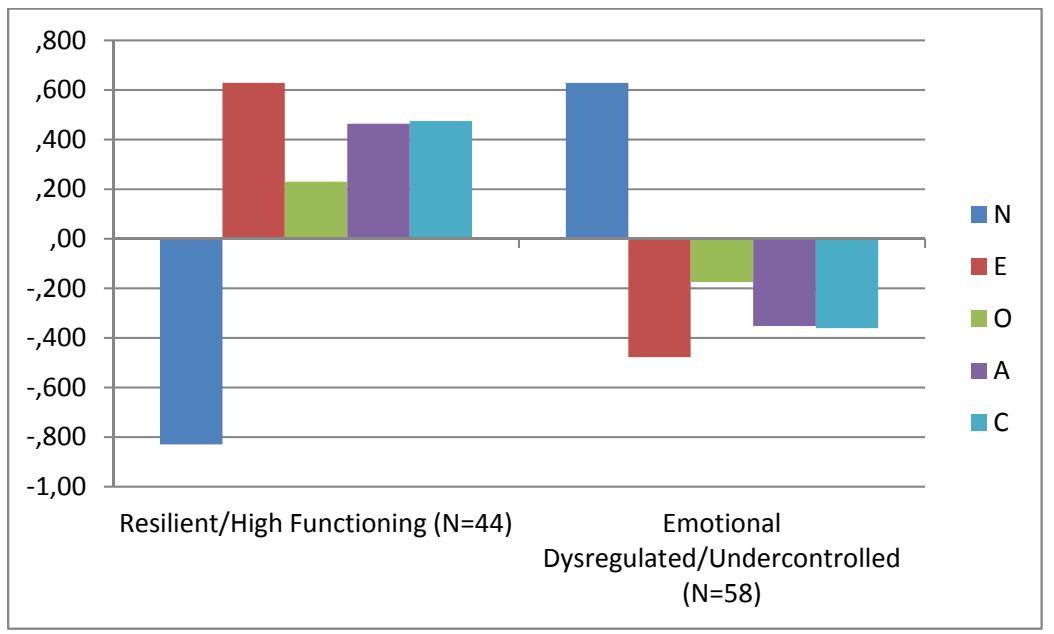

Figure 1. Two personality subtypes characterized by their standardized Big Five patterns in the female obese sample $(\mathrm{N}=102)$. 
Table 1. Means and standard deviations of the NEO-FFI scales for the RHF and the EDU subtypes

\begin{tabular}{|c|c|c|c|c|c|}
\hline & \multicolumn{2}{|c|}{ RHF } & \multicolumn{2}{|c|}{ EDU } & \\
\hline & & & & & \\
\hline & $\mathrm{M}$ & (SD) & $\mathrm{M}$ & (SD) & $F$ \\
\hline NEO-Neuroticism & 28.88 & $(5.56)$ & 40.20 & $(5.21)$ & $111.25 * * *$ \\
\hline NEO-FFI Extraversion & 44.77 & $(4.37)$ & 37.98 & $(5.67)$ & $43.45 * * *$ \\
\hline NEO-FFI Openness & 37.15 & $(5.75)$ & 34.91 & $(5.23)$ & $4.22 *$ \\
\hline NEO-FFI Agreeableness & 47.56 & $(4.79)$ & 43.65 & (4.09) & $19.72 * * *$ \\
\hline NEO-FFI Conscientiousness & 48.00 & $(5.06)$ & 43.22 & $(5.34)$ & $20.90 * * *$ \\
\hline
\end{tabular}

$* \mathrm{p}<0.05, * * \mathrm{p}<0.01, * * * \mathrm{p}<0.001$

RHF $=$ Resilient/High Functioning subtype; EDU = Emotional Dysregulated/Undercontrolled subtype 
Table 2. Means and standard deviations of the BMI, Weight Fluctuation, EDE-Q and DEBQ scales for the RHF and EDU subtypes

\begin{tabular}{|c|c|c|c|c|c|}
\hline & \multirow{2}{*}{\multicolumn{2}{|c|}{$\begin{array}{c}\text { RHF } \\
(\mathrm{N}=44)\end{array}$}} & \multirow{2}{*}{\multicolumn{2}{|c|}{$\begin{array}{c}\text { EDU } \\
(\mathrm{N}=58)\end{array}$}} & \multirow[b]{3}{*}{$F$} \\
\hline & & & & & \\
\hline & $\mathrm{M}$ & (SD) & $\mathrm{M}$ & (SD) & \\
\hline BMI & 40.90 & $(3.69)$ & 40.60 & $(4.52)$ & 0.13 \\
\hline Weight-Fluctuation & 41.52 & $(14.52)$ & 41.62 & (13.91) & 0.00 \\
\hline EDE-Q Restraint & 1.34 & $(0.93)$ & 1.39 & $(1.19)$ & 0.04 \\
\hline EDE-Q Eating Concern & 1.08 & $(0.96)$ & 2.14 & $(1.22)$ & $18.43 * * *$ \\
\hline EDE-Q Weight Concern & 2.86 & $(1.17)$ & 3.71 & $(1.10)$ & $11.85 * * *$ \\
\hline EDE-Q Shape Concern & 3.69 & $(1.27)$ & 4.41 & $(1.10)$ & $7.97 * *$ \\
\hline DEBQ-Restraint Eating & 3.18 & $(0.63)$ & 2.88 & $(0.55)$ & $6.26^{* *}$ \\
\hline DEBQ-Emotional Eating & 2.30 & $(0.90)$ & 2.84 & $(0.91)$ & $8.14 * *$ \\
\hline DEBQ-External Eating & 2.83 & $(0.69)$ & 3.13 & $(0.64)$ & $4.71 *$ \\
\hline
\end{tabular}

$* \mathrm{p}<0.05, * * \mathrm{p}<0.01, * * * \mathrm{p}<0.001$

RHF $=$ Resilient/High Functioning subtype; EDU = Emotional Dysregulated/Undercontrolled subtype 
Table 3. Means and standard deviations of the SCL-90 scales for the RHF and EDU subtypes

\begin{tabular}{|c|c|c|c|c|c|}
\hline & \multirow{2}{*}{\multicolumn{2}{|c|}{$\begin{array}{c}\text { RHF } \\
(\mathrm{N}=44)\end{array}$}} & \multicolumn{2}{|c|}{ EDU } & \multirow[b]{3}{*}{$F$} \\
\hline & & & $(\mathrm{N}=$ & 58) & \\
\hline & $\mathrm{M}$ & (SD) & M & (SD) & \\
\hline SCL Agoraphobia & 8.09 & $(1.88)$ & 11.54 & $(5.63)$ & $14.45^{* * *}$ \\
\hline SCL Anxiety & 13.16 & $(3.29)$ & 17.26 & $(6.58)$ & $13.55^{* * *}$ \\
\hline SCL Depression & 25.02 & $(7.05)$ & 34.32 & $(11.26)$ & $21.81 * * *$ \\
\hline SCL Somatisation & 22.28 & $(5.88)$ & 26.75 & $(7.54)$ & $9.93 * *$ \\
\hline SCL Insufficiency & 15.35 & $(4.92)$ & 18.60 & $(6.39)$ & $7.35^{* *}$ \\
\hline SCL Interpersonal Sensitivity & 26.88 & $(7.25)$ & 38.07 & $(11.72)$ & $29.34 * * *$ \\
\hline SCL Hostility & 7.28 & $(1.67)$ & 9.45 & $(3.68)$ & $12.45^{* * *}$ \\
\hline SCL Sleeping Problems & 6.59 & (3.29) & 6.35 & $(3.17)$ & 0.12 \\
\hline SCL Psychoticism & 12.45 & $(2.83)$ & 16.37 & $(4.81)$ & $21.87 * * *$ \\
\hline SCL Psychoneuroticism & 137.14 & $(28.27)$ & 178.75 & $(49.98)$ & $23.19 * * *$ \\
\hline
\end{tabular}

RHF $=$ Resilient/High Functioning subtype; EDU = Emotional Dysregulated/Undercontrolled subtype 
Table 4. Means and standard deviations of the UCL scales for the RHF and EDU subtypes

\begin{tabular}{|c|c|c|c|c|c|}
\hline & \multirow{2}{*}{\multicolumn{2}{|c|}{$\begin{array}{c}\text { RHF } \\
(\mathrm{N}=44)\end{array}$}} & \multirow{2}{*}{\multicolumn{2}{|c|}{$\begin{array}{c}\text { EDU } \\
(\mathrm{N}=58)\end{array}$}} & \multirow[b]{3}{*}{$F$} \\
\hline & & & & & \\
\hline & M & (SD) & M & (SD) & \\
\hline UCL-Active Problem Solving & 18.84 & $(3.58)$ & 16.55 & $(3.12)$ & $11.59 * * *$ \\
\hline UCL-Palliative Reactions & 16.47 & $(3.09)$ & 17.78 & $(2.88)$ & $4.76^{*}$ \\
\hline UCL-Avoidance & 14.95 & $(2.47)$ & 17.07 & $(3.26)$ & $12.70^{* * *}$ \\
\hline UCL-Social Support & 14.97 & $(3.54)$ & 14.28 & $(3.46)$ & 0.96 \\
\hline UCL-Depressive Reactions & 10.22 & $(2.26)$ & 13.33 & $(3.35)$ & $27.89 * * *$ \\
\hline UCL-Expression of Emotions & 6.38 & $(1.71)$ & 6.66 & $(1.71)$ & 0.62 \\
\hline UCL-Self-Soothing Thoughts & 13.04 & $(3.04)$ & 12.60 & $(2.28)$ & 0.67 \\
\hline
\end{tabular}

RHF $=$ Resilient/High Functioning subtype; EDU = Emotional Dysregulated/Undercontrolled subtype 